\title{
Class A predictions of a NATM tunnel in stiff clay
}

\author{
T. Svoboda, D. Mašín ${ }^{1}$ and J. Boháč \\ Charles University in Prague \\ Institute of Hydrogeology, Engineering Geology and Applied Geophysics \\ Albertov 6 \\ 12843 Prague 2, Czech Republic \\ E-mail:masin@natur.cuni.cz \\ Tel: +420-2-2195 1552, Fax: +420-2-21951556
}

June 23, 2010

Submitted to Computers and Geotechnics

${ }^{1}$ corresponding author 


\section{Abstract}

The paper demonstrates the application of a hypoplastic model in class A predictions of a NATM tunnel in an urban environment. The tunnel, excavated in a stiff clay, is $14 \mathrm{~m}$ wide with $6 \mathrm{~m}$ to $21 \mathrm{~m}$ of overburden thickness. The constitutive model was calibrated using laboratory data (oedometric and triaxial tests) and the parameters were optimised using monitoring data from an exploratory drift. Based on the optimised data set, the future tunnel was simulated. After the tunnel excavation, it could be concluded that the model predicted correctly surface settlements, surface horizontal displacements, and the distribution of vertical displacements with depth. It overpredicted horizontal displacements in the vicinity of the tunnel.

Key Words: Nonlinear analysis; Tunnelling; Clays; Constitutive models; Three-dimensional analysis; Class A predictions

\section{Introduction}

The main issue of tunnelling in urban environment, typically characterised by a low overburden thickness and presence of surface infrastructure, is the control of settlements induced by tunnel excavation. The first step in the design of any protective measure reducing the tunnel impact on surrounding buildings is an accurate prediction of the tunnelling-induced displacement field.

Predictions of displacements induced by tunnelling in fine-grained soils, which are in scope of this paper, were studied by a number of researchers. Currently, it is well accepted that the crucial role in predictions is played by the soil constitutive model, in particular its ability of predicting the very-small-strain stiffness and its non-linear decrease with further straining [1, 13, 6, 9, 10, 37, 21]. Further improvement in the predictions is achieved by considering of the soil anisotropy [1, 13, 9]. Tunneling is clearly a three-dimensional problem and consideration of 3D effects has thus also an important impact on the predictions (see [21] for overview). Further, the results are significantly influenced by the initial conditions. Particularly of the coefficient of earth pressure at rest $K_{0}[9,7]$, whose value is often uncertain.

The present paper demonstrates the application of an advanced constitutive model [19] in predictions of a complex tunnelling problem in urban environment. The goal was to provide class A [18] predictions of the displacement field induced by a $14 \mathrm{~m}$ wide road tunnel in stiff clay, with an overburden of $6 \mathrm{~m}$ to $21 \mathrm{~m}$. The parameters of the constitutive model were calibrated on laboratory data and optimised using monitoring data from an exploratory drift. The drift was located in top heading of the future tunnel. Based on the optimised data set, class A predictions of the displacement field induced by the tunnel were performed in 2008 and early 2009. In November 2009, the full profile of the tunnel passed the simulated cross-section, which allowed us to compare the predictions with the data from the geotechnical monitoring. 


\section{Královo Pole tunnels}

The Královo Pole tunnels (often referred to as Dobrovského tunnels) form a part of the northern section of the ring road of Brno town in the Czech Republic. The tunnels consist of two parallel tubes with a separation distance of about $70 \mathrm{~m}$ and lengths of approximately $1250 \mathrm{~m}$. The tunnel cross-section height and width are about $12 \mathrm{~m}$ and $14 \mathrm{~m}$ respectively, and the overburden thickness varies from $6 \mathrm{~m}$ to $21 \mathrm{~m}$. The tunnels are driven in developed urban environment (see Fig. 1). The displacement field induced by the tunnel excavation was thus an important issue the designers had to cope with.

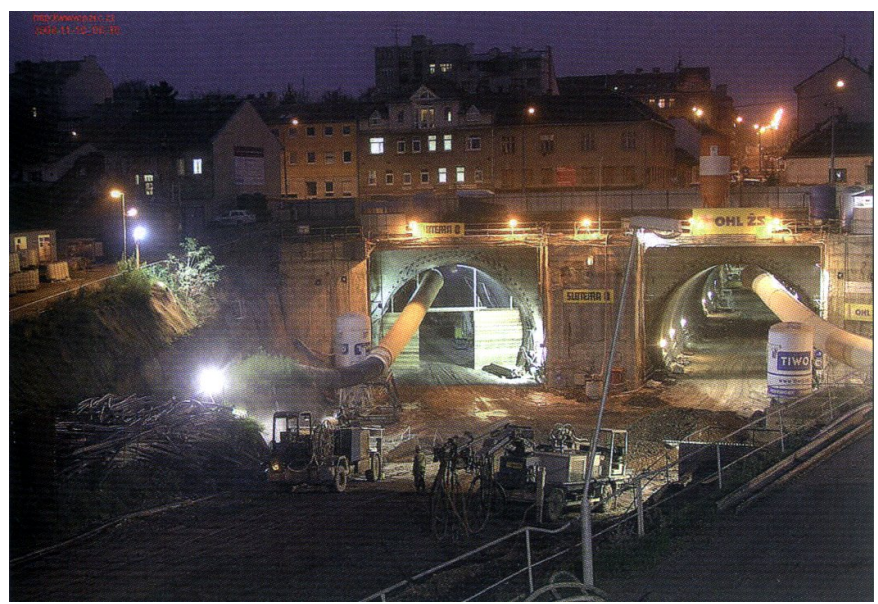

Figure 1: Temporary portals of the Královo Pole tunnels (Horák [15]).

The geological sequence in the area is shown in Fig. 2. From the stratigraphical point of view, the area is formed by Miocene marine deposits of the Carpathian fore-trough, the thickness of which reaches several hundreds meters in this location [27]. The top part of the overburden consists of anthropogenic materials. The natural Quaternary cover consists of loess loam and clayey loam with the thickness of 3 to $10 \mathrm{~m}$. The base of the Quaternary cover is formed by a discontinuous layer of fluvial sandy gravel, often with a loamy admixture. The majority of the tunnel is driven through the Tertiary calcareous silty clay. In the upper part the clay is tinted rusty-brown due to limonitic solutions penetrating through discontinuity systems, the fresh clay is of green-grey color (Fig. 3b). The thickness of the clay deposit is presumed to be several hundreds of meters. The bedrock was not encountered by $60 \mathrm{~m}$ long boreholes [16]. The clays are of stiff to very stiff consistency and high plasticity. They disintegrate to blocks or small fragments; main fault planes are slickensided and uneven. The water table is located in the Quarternary sandy-gravel strata.

Before the Královo Pole project, there was only little experience with the response of the Brno clay to tunnelling. In order to clarify the geological conditions of the site, and in order to study the mechanical response of the Brno clay, a comprehensive geotechnical site investigation programme was designed, the crucial part of it being an excavation of three exploratory drifts [38]. The drifts were triangular in cross section with the side-length of $5 \mathrm{~m}$ and were designed to form parts of the top headings of the future tunnels (see Fig. 3). The total length of the three drifts was over 2000 $\mathrm{m}$. For technological reasons, they were not driven along the complete length of the future tunnels. 


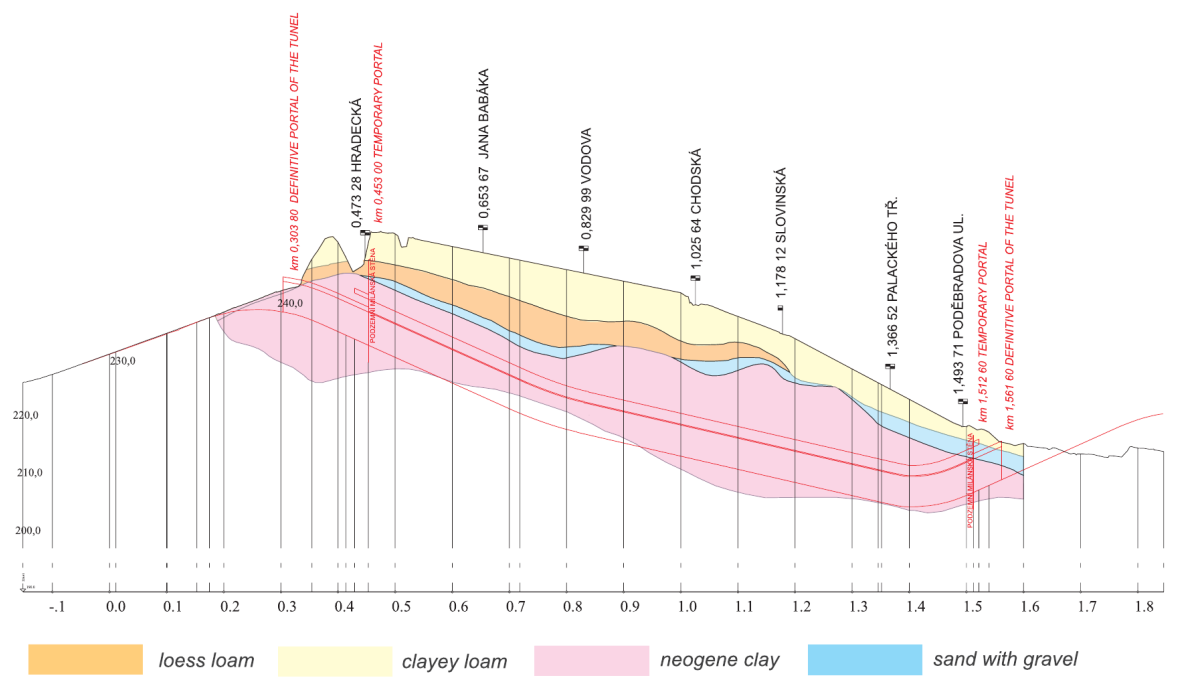

Figure 2: Longitudinal geological cross-section along the tunnels (Pavlík et al. [27]).

The drifts were excavated in the period of 2002 to 2003.

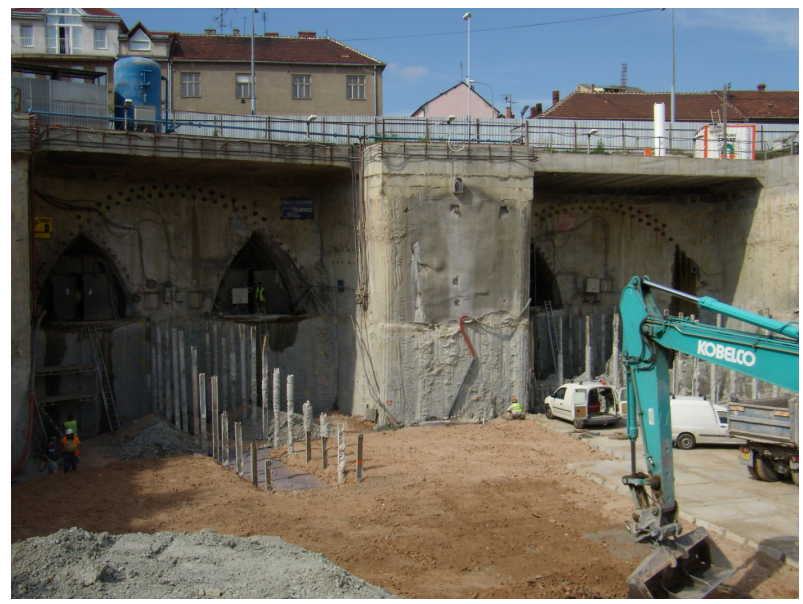

(a)

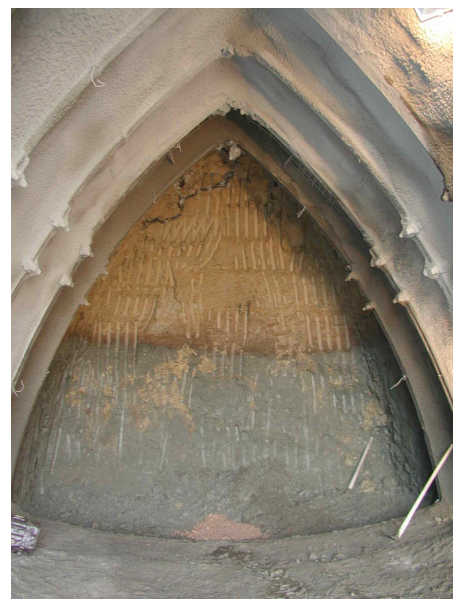

(b)

Figure 3: (a) Exploratory drifts situated in the top headings of the future Královo Pole tunnels; (b) detail of the drift with the boundary between weathered and non-weathered Brno clay (Pavlík et al. [28]).

The impact of the excavation of the drifts on the surrounding buildings was bigger than expected. Therefore, before the excavation of the tunnels, a number of protective measures to prevent the damage of the existing buildings was adopted (such as compensation grouting). A detailed description of these measures is outside the scope of the present paper and may be found elsewhere (for example, [15]).

The excavation of the tunnels commenced in January 2008. The tunnels were driven by the New Austrian Tunneling Method (NATM), with sub-division of the face into six separate headings (Fig. 
4). The face subdivision, and the relatively complicated excavation sequence (Fig. 4), were adopted in order to minimise the surface settlements imposed by the tunnel [4]. The tunnelling always proceeds at three partial headings (b,c,e - a,d,f), which exchange within a step of 8-12 $\mathrm{m}$ in a threeday cycle. This means that each of the separate headings proceeds $8-12 \mathrm{~m}$ during 6 days. The inactive headings are protected by shotcrete. The unsupported span (one excavation step) is $1.2 \mathrm{~m}$. The excavation of the tunnels is planned to finish in 2010 .

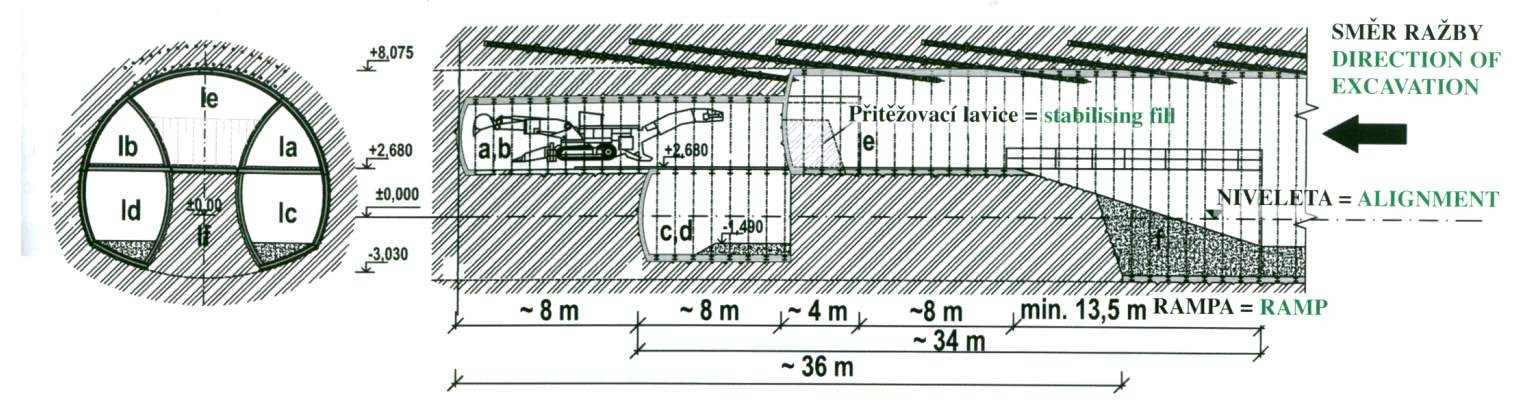

Figure 4: Sketch of the excavation sequence of the tunnel (Horák [15]).

\section{Laboratory experiments}

As demonstrated later in the text, the behaviour of loess loams and sandy gravels was found not to influence significantly the predicted tunnel performance, the laboratory experiments thus focused on the behaviour of Brno clay. Samples from two boreholes (in the tunnel centerline and 1.5 $\mathrm{m}$ from the tunnel cross-section) were used in the investigation. Three undisturbed samples were taken from each borehole from different depths (15.5 $\mathrm{m}$ to $19.5 \mathrm{~m}$ ) using thin-walled steel samplers.

From two of the samples, triaxial specimens of the diameter of $38 \mathrm{~mm}$ were prepared (three undisturbed specimens from each sample). The specimens were tested in triaxial shear under undrained conditions (CIUP tests). Standard platens were used without any measures to reduce end friction, and all the specimens were equipped with radial drainage. All specimens were isotropically consolidated up to different stress levels $(280,500$ and $750 \mathrm{kPa})$ and then sheared with constant axial strain rate. The specimens were equipped with submersible local LVDT axial strain transducers in order to evaluate the soil stiffness in the small strain range. In addition, one specimen was equipped with bender elements to measure the soil stiffness in the very small strain range by means of propagation of shear waves. Results of the experiments are presented in the next section together with the constitutive model calibration.

In addition to the triaxial tests, oedometric tests have been performed on undisturbed and reconstituted specimens. The specimens were loaded up to axial pressures of $13 \mathrm{MPa}$ in order to find the position of the normal compression line and in order to evaluate the apparent overconsolidation ratio, which is used for estimation of the coefficient of earth pressure at rest $K_{0}$. Finally, a set of ring-shear tests on reconstituted specimens has been performed. Following Najser and Boháč [24], peak friction angle on normally consolidated reconstituted specimens evaluated in ring-shear apparatus is considered to be an estimation of the critical state friction angle of soil. 


\section{Constitutive model and parameter calibration}

The mechanical behaviour of the Brno clay was simulated using the hypoplastic model for clays (Mašín [19]) enhanced by the concept of intergranular strains (Niemunis and Herle [25]). This model was selected to represent the advanced constitutive models, which are capable of predicting the non-linear soil behaviour, with high stiffness at very small strains and a nonlinear decrease of stiffness with increasing strain level. Physically, the model is based on the critical state soil mechanics (see Gudehus and Mašín [12]). For evaluation of the predictive capabilities of the model see $[22,14]$. The implementation of the model into various finite element programs (such as Plaxis, ABAQUS, Tochnog Professional) is freely available on the internet [11].

The basic version of the hypoplastic model requires five parameters, whose physical interpretation corresponds to the parameters of the Modified Cam-Clay model [32]: $N, \lambda^{*}, \kappa^{*}, \varphi_{c}$ and $r$. The parameters $N$ and $\lambda^{*}$ define the position and the slope of the isotropic normal compression line (NCL) within the $\ln p$ vs. $\ln (1+e)$ representation, where $p$ is the effective mean stress and $e$ is the void ratio. Parameter $\kappa^{*}$ controls the slope of the isotropic unloading line. The above-mentioned three parameters were calibrated using the results of the oedometer test on an undisturbed sample of the Brno clay, see Fig. 5. In this way, the effects of natural structure were directly taken into account. The obtained parameters $N, \lambda^{*}$ and $\kappa^{*}$ thus do not necessarily represent the intrinsic values that would be obtained by calibration of the model using data from reconstituted specimens. This approach is possible as the Brno clay is stiff. In such a type of soil, stable elements of structure $[3,5]$ prevail, and it is thus not necessary to adopt more advanced model (such as [20]) that explicitly incorporates structure degradation.

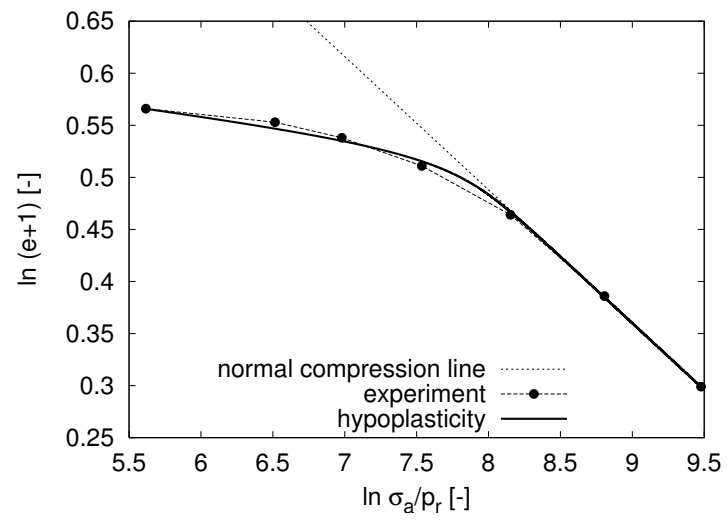

Figure 5: Calibration of the hypoplastic model using oedometric test on undisturbed Brno clay sample.

Parameter $\varphi_{c}$ is the critical state friction angle, which was calibrated using the ring shear tests (where the measured peak strength was assumed to correspond to the critical state strength [24]). The parameter $r$, controlling the soil shear stiffness, was derived from CIUP triaxial tests on the undisturbed samples (see Fig. 6). Figure 6a shows the deviator stress versus axial strain; Figure $6 \mathrm{~b}$ presents the undrained stress paths. The hypoplastic model does not consider any parameter controlling the peak strength. It is implied by the value of $\varphi_{c}$ and by overconsolidation ratio. Fig. 6 shows that in the present case the hypoplastic model underestimated the peak friction angle. This 
fact is not crucial in the present simulations, as the results are mostly controlled by the soil stiffness (Sec. 6.1). It also does not show any general deficiency of the hypoplastic model - adequacy of predictions of the peak friction angle was studied in Ref. [14].

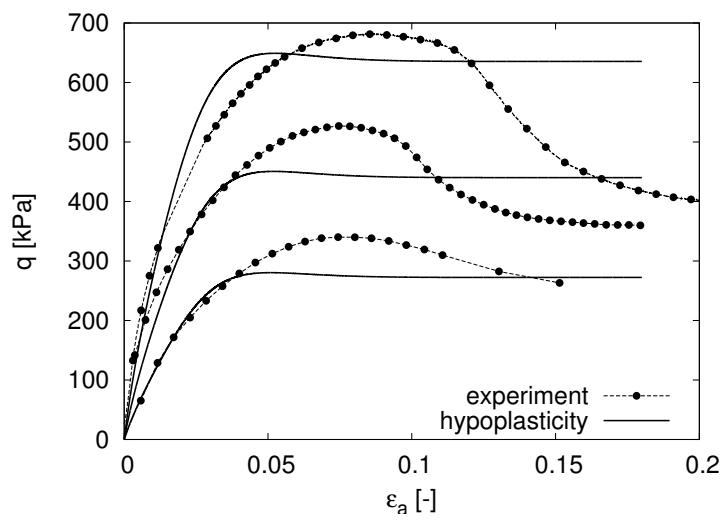

(a)

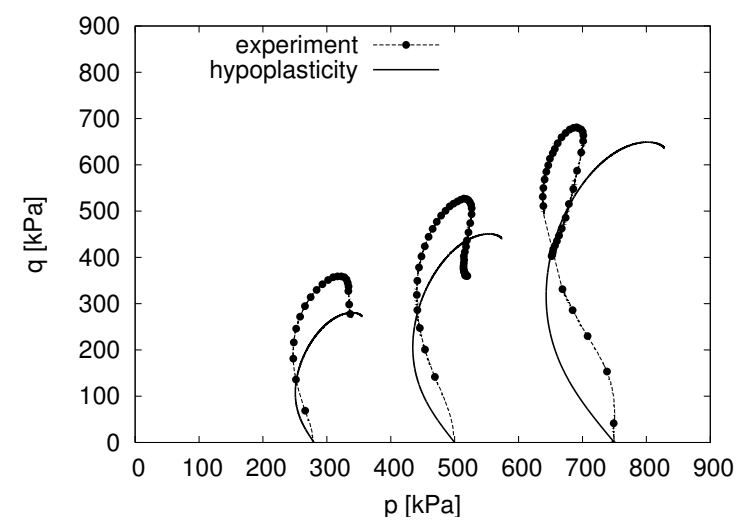

(b)

Figure 6: Calibration of the hypoplastic model using undrained triaxial test on undisturbed Brno clay samples. $p_{r}$ is the reference stress $1 \mathrm{kPa}$.

The basic hypoplastic model predicts the soil behaviour in the medium to large strain range. In order to predict the high initial (very-small strain) stiffness, its decrease with straining, and the effects of recent stress (deformation) history [2], the model needs to be enhanced by the intergranular strain concept [25]. The concept requires additional five parameters $\left(m_{R}, m_{T}, R, \beta_{r}\right.$ and $\left.\chi\right)$. The parameters $m_{R}$ and $m_{T}$ influence the initial (very-small-strain) shear modulus through the equation [19]

$$
G_{0} \simeq \frac{m_{R}}{r \lambda^{*}} p
$$

The parameter $R$ controls the size of the elastic range and the remaining parameters $\beta_{r}$ and $\chi$ control the rate of the stiffness degradation. These parameters were found on the basis of the measurements of shear stiffness by means of LVDT gauges (Fig. 7b) and bender elements (see Fig. 7a). A trial-and-error procedure based on comparison of the predicted and experimental stiffness degradation curve was used. As is clear from Eq. (1) and Fig. 7a, the hypoplastic model predicts a linear increase of the initial shear modulus $G_{0}$ with mean stress. This linear increase of $G_{0}$ with $p$ does not correspond exactly to the trend of the experimental data. Therefore, the model was calibrated to reproduce correctly the $G_{0}$ at the stress level in the tunnel depth (namely, at $p=280$ $\mathrm{kPa})$.

Table 1 presents parameters of the hypoplastic model obtained by the calibration to experimental data.

Table 1: Brno clay parameters of the hypoplastic model.

\begin{tabular}{|ccccc|ccccc|}
\hline$\varphi_{c}$ & $\lambda^{*}$ & $\kappa^{*}$ & $N$ & $r$ & $m_{R}$ & $m_{T}$ & $R$ & $\beta_{r}$ & $\chi$ \\
$19.9^{\circ}$ & 0.128 & 0.01 & 1.506 & 0.45 & 16.75 & 16.75 & 0.0001 & 0.2 & 0.8 \\
\hline
\end{tabular}




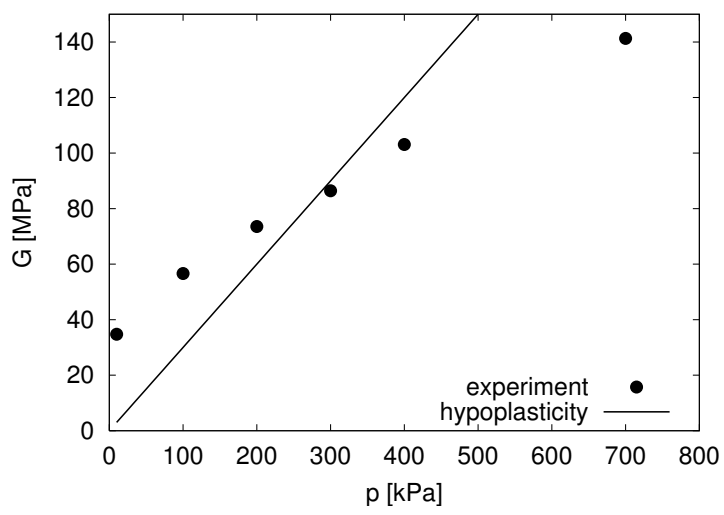

(a)

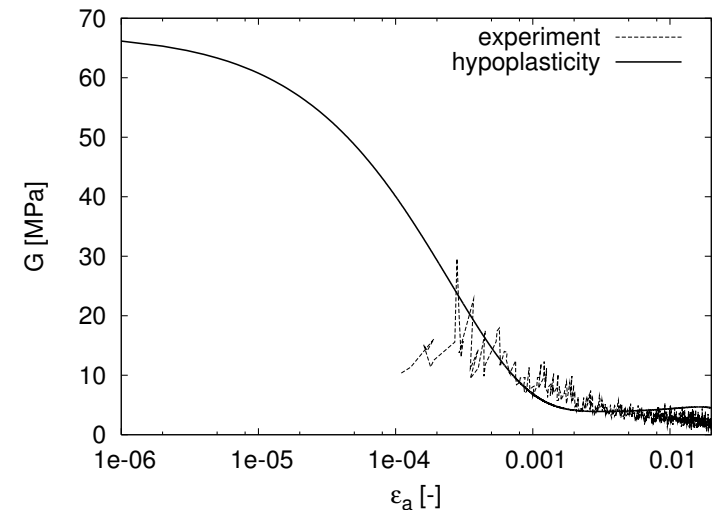

(b)

Figure 7: Calibration of the hypoplastic model using small-strain-stiffness measurements on undisturbed Brno clay samples.

\section{Simulation of the exploratory drift and optimisation of the model parameters}

The finite element predictions of the exploratory drift and of the whole tunnel were performed using software Tochnog Professional [31]. The geometry of the exploratory drift and the finite element mesh consisting of 4680 8-noded brick elements are shown in Fig. 8. The evaluated cross-section corresponded to the front boundary of the finite element model. It was checked that no additional displacements at the evaluated cross-section are caused by the further advance of the drift face. Steady state conditions were thus reached. The mesh density was selected to be approximately the same for the drift and full tunnel simulations (Sec. 7). CPU demands of the full tunnel simulations did not allow for further mesh refinements. The analyses were performed as undrained using penalty approach with bulk modulus of water equal to $K_{w}=100 \mathrm{MPa}$. This procedure is described in Mašín [21]. No interface elements have been used between the tunnel lining and the soil; therefore sliding of the lining with respect to soil has not been allowed which is a reasonable assumption for shotcrete lining. On the vertical sides of the mesh, normal horizontal movements have been restrained, whereas the base has been fixed in all directions.

The bottom $27.7 \mathrm{~m}$ thick stratum represent the Brno clay and it has been simulated using the hypoplastic model with parameters from Tab. 1. The overlying layers of loams and gravels were simulated using the Mohr-Coulomb model with the parameters obtained during the site investigation [28] (Table 2). The shotcrete lining was simulated using continuum elements in the 3D model. Its was modelled by a linear elasticity with time dependent stiffness calculated using an empirical relationship [30, 26]

$$
E=E_{f}\left(1-e^{-\alpha t / t_{r}}\right)
$$

where $E_{f}$ is the final Young modulus, $\alpha$ is a parameter and $t_{r}=1$ day is the reference time. The same parameters as the ones adopted by Mašín [21] were used in the simulations ( $E_{f}=14.5 \mathrm{GPa}$ and $\alpha=0.14$ ). The simulated excavation sequence represented the one adopted on the site. An excavation step of $1.2 \mathrm{~m}$ was followed by the lining installation. 
Table 2: Mohr-Coulomb model parameters of the layers overlying the Brno clay strata.

\begin{tabular}{|l|ccccc|}
\hline soil & $\varphi\left[^{\circ}\right]$ & $c[\mathrm{MPa}]$ & $\psi\left[^{\circ}\right]$ & $E[\mathrm{MPa}]$ & $\nu$ \\
\hline backfill & 20 & 10 & 4 & 10 & 0.35 \\
loess & 28 & 2 & 2 & 45 & 0.4 \\
sandy gravel & 30 & 5 & 8 & 60 & 0.35 \\
\hline
\end{tabular}

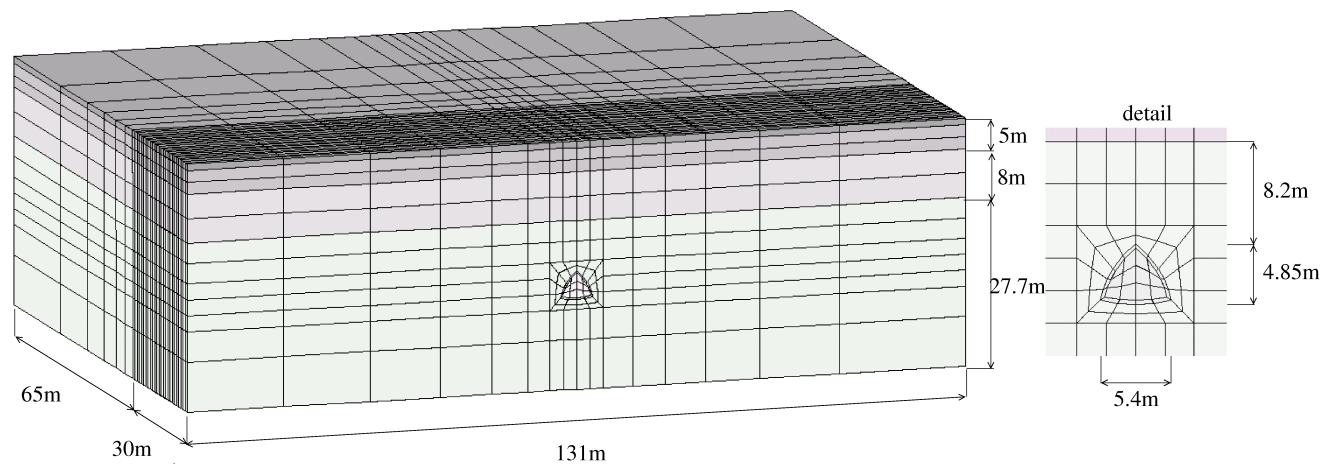

Figure 8: Finite element mesh used in the analyses of the exploratory drift.

The initial conditions of the simulation consisted of the determination of vertical stresses, the void ratio and the coefficient of earth pressure at rest $K_{0}$. The vertical stress was calculated from the unit weight of soil: $\gamma=18.8 \mathrm{kN} / \mathrm{m}^{3}$ for clay, $19.5 \mathrm{kN} / \mathrm{m}^{3}$ for secondary loess and $19.6 \mathrm{kN} / \mathrm{m}^{3}$ for sandy gravels. Water table corresponded to the Brno clay - sandy gravel interface. The initial void ratio of the Brno clay $\mathrm{e}=0.83$ was derived from the undisturbed samples from both boreholes.

Because no reliable in-situ measurements of $K_{0}$ were available in the Brno clay massif, two extreme values of $K_{0}$ were considered in the analyses. First, the value of $K_{0}$ was determined from Mayne and Kulhawy [23] empirical relationship:

$$
K_{0}=\left(1-\sin \varphi_{c}\right) O C R^{\sin \varphi_{c}}
$$

The overconsolidation stress of $1800 \mathrm{kPa}$ was estimated on the basis of the oedometer tests on the undisturbed Brno clay samples (see Fig. 5), with the corresponding overconsolidation ratio (OCR) of 6.5, leading to $K_{0}=1.25$. The calculation of $K_{0}$ according to Eq. (3) assumes that the apparent soil overconsolidation was caused by the actual soil unloading resulting from the erosion of overlying geological layers. Creep represents the second possible interpretation of the measured overconsolidation. This interpretation would lead to the $K_{0}$ value calculated from the Jáky [17] relationship:

$$
K_{0}=1-\sin \varphi_{c}
$$

leading to $K_{0}=0.66$. $K_{0}$ of the layers overlying Brno clay was always calculated from (4) using the friction angle from Tab. 2.

The procedure of the analyses was as follows. First, the drift was simulated using the 3D finite element method. The next step was optimisation of the model parameters to account for inaccuracies 
of the description of soil massif based on small-size laboratory specimens. As the optimisation was CPU demanding and not feasible in 3D, an equivalent 2D model to the presented 3D model was developed. After the optimisation stage, the drift was simulated in 3D using the optimised parameter set. The 2D model was based on the load reduction method [33]. The load reduction factor $\lambda^{d}$ was calculated to ensure that the 3D analyses and the equivalent 2D analyses predicted as closely as possible the surface settlement troughs. The actual factors $\lambda_{d}$ for the drift simulations were $\lambda_{d}=0.50$ (for $K_{0}=1.25$ ) and $\lambda_{d}=0.53$ (for $K_{0}=1.66$ ). The adequacy of the $2 \mathrm{D}$ representation has been demonstrated in a separate paper [36]. The 3D and equivalent 2D models gave comparable predictions of the displacement fields, apart from the displacements in the very close vicinity of the tunnels.

\subsection{Analyses of sensitivity}

In order to clarify the influence of the individual soil layers and different parameters on the results of the simulations, a sensitivity analysis has been performed. The sensitivity analysis, as well as the optimisation analysis presented in Sec. 6.2, have been performed using the software UCODE [29] using the 2D model based on the load reduction method. In the analyses, results of the simulations are compared with the measurement of the vertical displacements at several locations. Three locations were at the surface, where the vertical displacements were measured by means of geodetic survey. The fourth monitoring point was located just above the drift crown and it was monitored by means of an extensometer. The differences between the simulation and the monitoring data were expressed in terms of an objective function $S(b)$ [8] which takes the form:

$$
S(b)=\left[y-y^{\prime}(b)\right]^{T} \omega\left[y-y^{\prime}(b)\right]
$$

where $b$ is a vector containing the values of parameters, $y$ is a vector of observations, $y^{\prime}(b)$ is a vector of the computed values corresponding to the observations and $\omega$ is the weight matrix. The weight matrix evaluates the significance of each measurement. Typically, the weight of each observation is taken as the inverse of its error variance [8]. In the present case, with a low number of observations, however, each of the four observations is given the same weight equal to unity.

The sensitivity of the results to the variation of each of the paremeters may be evaluated in terms of a composite scaled sensitivity $\operatorname{css}_{j}$ defined as

$$
\operatorname{css}_{j}=\sqrt{\frac{1}{N D} \sum_{i=1}^{N D}\left(\left(\frac{\partial y_{i}^{\prime}}{\partial b_{j}}\right) b_{j} \omega_{i i}^{1 / 2}\right)^{2}}
$$

where $b_{j}$ is the $j$-th parameter being studied, $y_{i}^{\prime}$ is the $i$-th computed value, $\partial y_{i}^{\prime} / \partial b_{j}$ is sensitivity of the $i$-th computed value with respect to the $j$-th parameter, $\omega_{i i}$ is weight of the $i$-th observation and $N D$ is a number of observations.

The composite scaled sensitivities for the simulation of the exploratory drift with $K_{0}=1.25$ are shown in Fig. 9. The parameters without any subscript are the hypoplastic parameters of Brno clay, subscript $l s$ refers to the loess strata and $g r$ to the sandy gravel strata. In addition to the parameters of the constitutive models, Fig. 9 includes also the sensitivity of the results to the change of the state variables $K_{0}$ and $e$ (for Brno clay). 


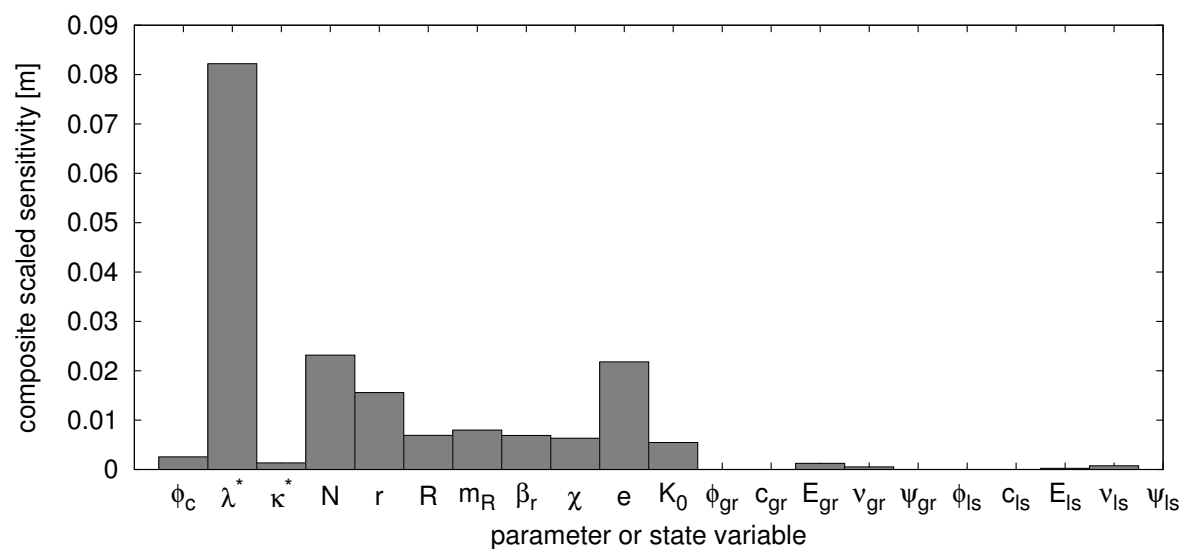

Figure 9: Composite scaled sensitivities for simulations of the exploratory drift.

A number of observations can be made by studying Fig. 9. First, it is clear that the soil strata overlying the Brno clay have a negligible effect on the results (although the adopted monitoring points included the surface measurements). For this reason, the laboratory program focused on the mechanical behaviour of Brno clay only. The very small influence of the critical state friction angle $\varphi_{c}$ indicates that the results are not influenced by the soil strength. This is consistent with the fact that the simulated tunnel is in an urban environment, with a low overburden thickness, where it is necessary to strictly ensure low settlements of the surrounding buildings. With such a tight criteria imposed on the settlements, the tunnel is typically in the safe zone from the stability point of view. The relatively significant influence of void ratio $e$ indicates that the assumed overconsolidation ratio has a considerable impact on the results. In fact, for the same reason also the influence of the parameters $\lambda^{*}$ and $N$ is high. These parameters influence the soil bulk modulus in the normally consolidated state. In the overconsolidated state (and thus also in the case of the stiff Brno clay), however, the major influence of the parameters $\lambda^{*}$ and $N$, which control the normal compression line, is through their impact on OCR. Apart from the value of $K_{0}$, the remaining influential parameters ( $r$ and the parameters of the intergranular strain concept) control the shear stiffness. The OCR can be estimated quite reliably (Fig. 5), the shear stiffness may thus be regarded as the most important characteristic controlling the results of the present simulations.

\subsection{Optimisation of the model parameters}

In geotechnical practice, a common problem is that due to the size effects, sampling disturbance and limitations of experimental devices laboratory specimens do not represent the behaviour of the soil massif with sufficient accuracy. For this reason, the soil parameters calibrated by means of laboratory experiments have been corrected using an inverse analysis of the exploratory drift [35]. The corrected parameters were then used for the class A predictions of the deformations due to the tunnel.

For the reasons explained above, in the optimisation stage we focused on the shear stiffness. Namely, the parameter $r$ controlling the large-strain shear stiffness as well as the small-strain shear stiffness (Eq. (1)) was optimised. As the value of $K_{0}$ has also remarkable influence on the results, 
all the simulations were performed with two extreme $K_{0}$ values (as explained above). The inverse analysis has been performed using the software UCODE. In the inverse analysis, the parameter values are automatically adjusted until the model's computed results match the observed behaviour of the system [8]. UCODE performs the optimisation by means of minimisation of the objective function $S(b)$ using the modified Gauss-Newton method.

The surface settlement troughs predicted with the original and optimised parameter sets, compared with the monitoring data, are shown in Fig. 10. Clearly, the model predicts reasonably both the settlement trough shape and magnitude already with the original parameter set. The optimisation procedure leads to a slight increase of the parameter $r$ (Tab. 3) and a further improvement in predictions.

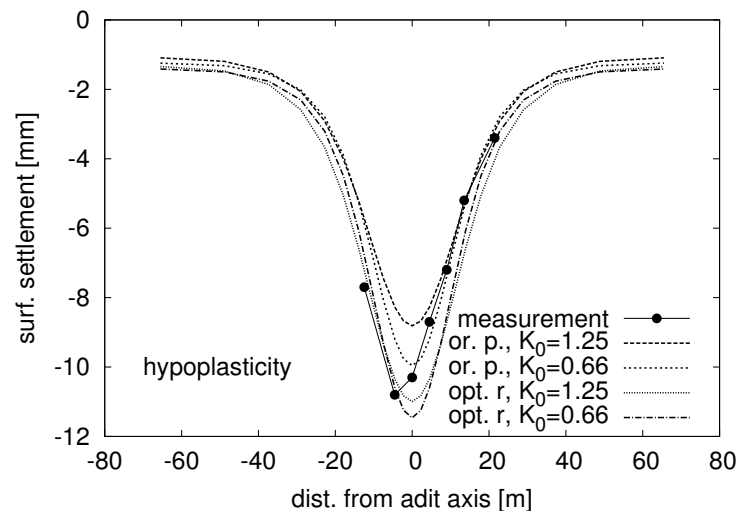

Figure 10: Surface settlement troughs due to exploratory drift predicted with the original parameter set ("or. p.") and with optimised value of the parameter $r$ ("opt. r").

Table 3: Original and optimised values of the parameter $r$.

\begin{tabular}{|l|l|}
\hline parameter set & $r$ \\
\hline original param. & 0.45 \\
optimised $r, K_{0}=1.25$ & 0.51 \\
optimised $r, K_{0}=0.66$ & 0.49 \\
\hline
\end{tabular}

\section{3D simulations of the Královo Pole tunnels}

As the last step in the investigation, the whole tunnel was simulated in $3 \mathrm{D}$ with the optimised parameter set. The results represent class A predictions, as they were performed in the period 2008 to early 2009, and thus before the tunnel excavation passed the simulated cross-section (November 2009). Before setup of the full 3D model, in early 2008, the authors simulated the problem in $2 \mathrm{D}$ using convergence-confinement method [34]. The 2D simulations predicted a settlement trough deeper by $40 \%$ than 3D simulations. This discrepancy was caused by the fact that in 2D simulations of the whole tunnel, the load-reduction factor $\lambda_{d}$ evaluated using the exploratory drift simulations 
was used. This value of $\lambda_{d}$ was later found inappropriate. The values of $\lambda_{d}$ based on 3D models of the whole tunnel were $\lambda_{d}=0.32$ for $K_{0}=1.25$ and $\lambda_{d}=0.35$ for $K_{0}=0.66$ respectively. For details, see Svoboda and Mašín [36].

In 3D, the finite element mesh consisting of 18352 8-noded elements was used. The mesh and the modelled geometry are shown in Fig. 11. As in the case of the drift simulations, the evaluated cross-section was located at the front tunnel boundary. Steady-state conditions with no additional displacements with further advance of the tunnel face were reached. Maximal mesh density allowed by the used CPU was adopted. No further check of the influence of mesh density was thus possible. Other details of the analyses (drainage conditions, boundary conditions) were the same as in the exploratory drift simulations (Sec. 6). The tunnel lining was modelled using continuum elements with the thickness of $0.35 \mathrm{~m}$ as a linear elastic material with time dependent stiffness (as in the case of the exploratory drift). A 100 meters long simulated portion of the tunnel corresponds to the tunnel chainage $0.790-0.890 \mathrm{~km}$ (Fig. 2). This section is not influenced by the protective measures (compensation grouting) mentioned in Sec. 3 and the monitored results thus represent green-field settlements. The models considered the complex excavation sequence with the tunnel face subdivided into 6 segments (Figure 12). The excavation was performed in steps 1 to 6 (Fig. 12) with an unsupported span of $1.2 \mathrm{~m}$. A constant distance of $8 \mathrm{~m}$ is kept between the individual faces, except the distance between the top heading and the bottom, which is $16 \mathrm{~m}$.
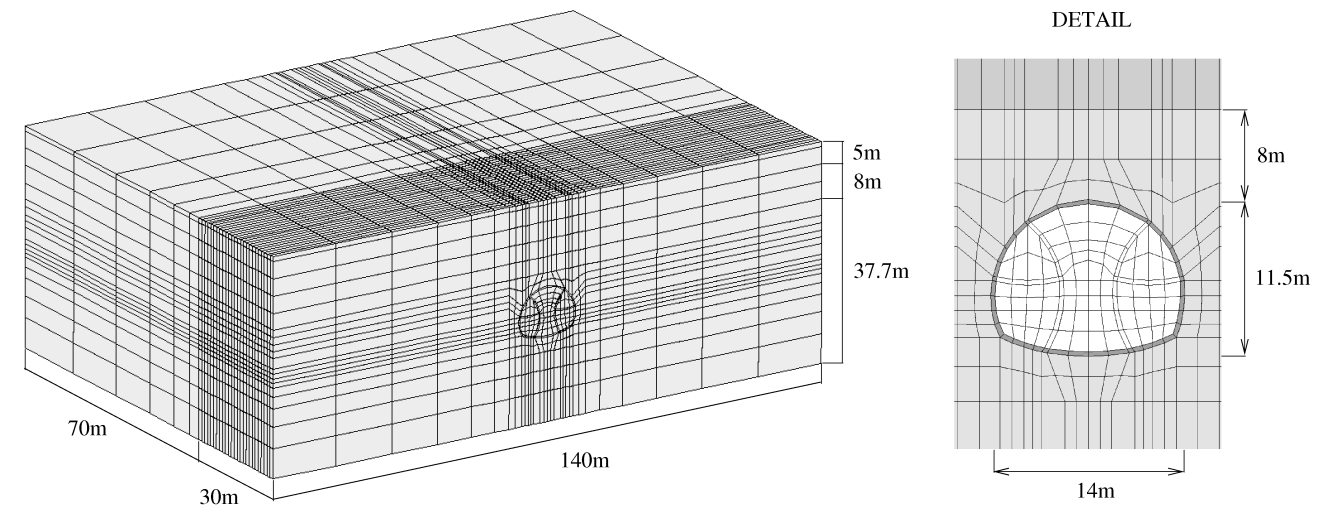

Figure 11: Finite element mesh used in the analyses of the whole tunnel.

The surface settlement troughs for both $K_{0}$ values are presented in Figure 13a. Due to the scatter of the monitoring data, several measurements at the chainages close to the simulated cross-section are presented. The agreement between the simulated and measured settlements is very good. The settlement magnitude is better predicted represented by the simulation with the higher $K_{0}$, while the trough shape is better predicted by the low $K_{0}$. Both predictions are on the safe side of the monitoring data (displacements are slightly overpredicted).

Figure $13 \mathrm{~b}$ shows measurements of an extensometer located above the tunnel crown. The difference between the monitoring data and the simulations is approximately constant with depth, and corresponds to the slight overestimation of the surface settlements in Fig. 13a. Fig. 13b thus indicates that the hypoplastic model predicts correctly also the distribution of vertical displacements 


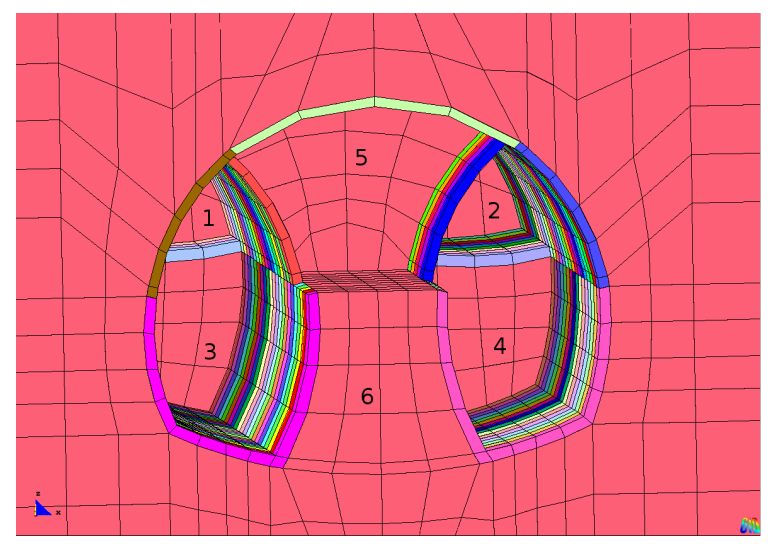

Figure 12: The excavation sequence as represented by the model.

with depth, not only surface settlements.

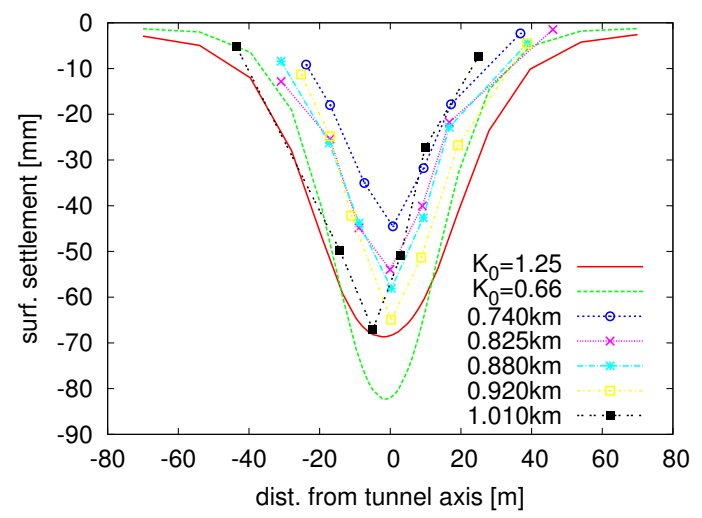

(a)

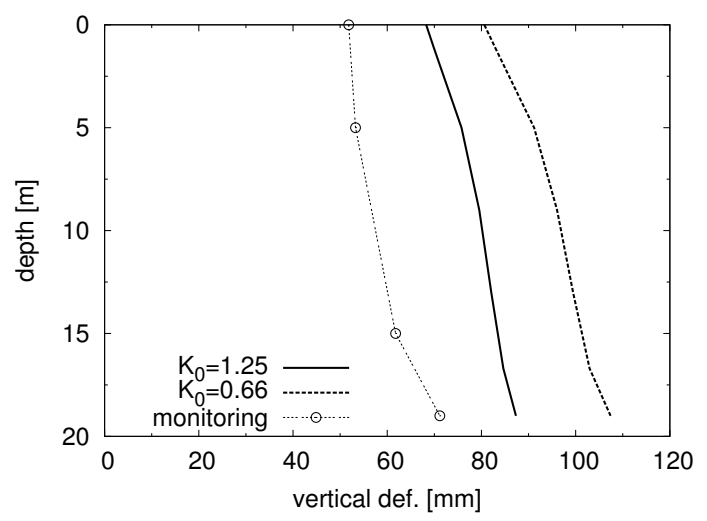

(b)

Figure 13: Surface settlement trough (a) and extensometer measurements (b). Class A predictions compared with the monitoring data.

Although the model predicts correctly the vertical displacement field, it significantly overestimates horizontal displacements in a vicinity of the tunnel in the tunnel depth. This is demonstrated in Fig. 14, showing the inclinometric measurements from an inclinometer located $3 \mathrm{~m}$ from the tunnel side. One of the possible reasons for this discrepancy is an absence of the small-strain stiffness anisotropy in the hypoplastic model. A similar problem was pointed out by Mašín [21], who concluded that incorporation of the small-strain stiffness anisotropy into the hypoplastic model would improve the predicted shape of the settlement trough. Importance of anisotropic stiffness in tunnel simulations was also discussed in Refs. [1, 13,9]. This indicates a direction for the future development of the hypoplastic model. At this point, however, it is necessary to stress out that although the horizontal displacements are overpredicted in the tunnel depth, their magnitude in the vicinity of the surface is predicted correctly. the correct predictions of the surface displacements are important in estimating the damage to the surrounding buildings. 


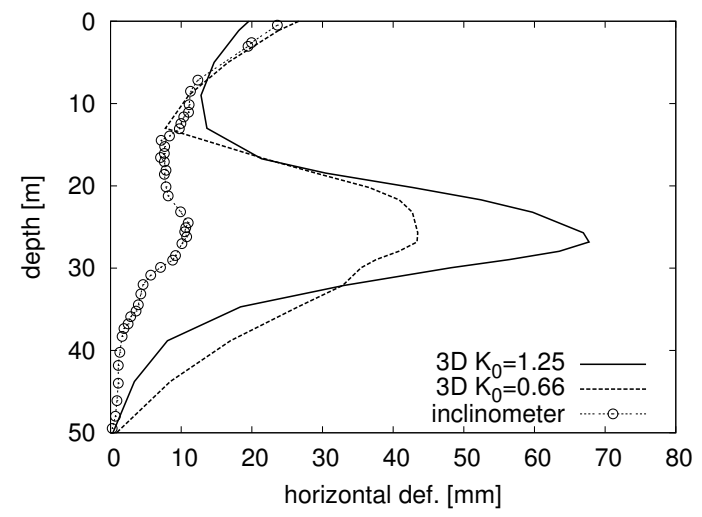

Figure 14: Inclinometric measurement, inclinometer located $3 \mathrm{~m}$ from the tunnel side.

\section{Concluding remarks}

It was shown that application of an advanced soil constitutive model, in combination with quality experimental data and 3D finite element analysis, may lead to accurate forward predictions of the displacement field induced by a tunnel with low overburden thickness. The hypoplastic model for clays enhanced by the intergranular strain concept gave accurate predictions of the surface settlement, surface horizontal displacements, and the distribution of vertical displacements with depths. For both $K_{0}$ values adopted the model overpredicted the horizontal displacements in the vicinity of the tunnel.

\section{Acknowledgment}

The authors greatly appreciate the financial support by the research grants GACR 205/08/0732, GAUK 134907 and MSM0021620855.

\section{References}

[1] T. Addenbrooke, D. Potts, and A. Puzrin. The influence of pre-failure soil stiffness on the numerical analysis of tunnel construction. Géotechnique, 47(3):693-712, 1997.

[2] J. H. Atkinson, D. Richardson, and S. E. Stallebrass. Effects of recent stress history on the stiffness of over-consolidated soil. Géotechnique, 40(4):531-540, 1990.

[3] B. A. Baudet and S. E. Stallebrass. A constitutive model for structured clays. Géotechnique, 54(4):269-278, 2004.

[4] J. Bača and V. Dohnálek. Královo Pole tunnels - experience obtained during the construction to date. Tunel, 18(3):27-32, 2009. 
[5] F. Cotecchia and J. Chandler. A general framework for the mechanical behaviour of clays. Géotechnique, 50(4):431-447, 2000.

[6] G. R. Dasari, C. G. Rawlings, and M. D. Bolton. Numerical modelling of a NATM tunnel construction in London Clay. In R. J. Mair and R. N. Taylor, editors, Geotechnical Aspects of Underground Construction in Soft Ground, pages 491-496. A.A.Balkema, Rotterdam, 1996.

[7] M. Doležalová. Approaches to numerical modelling of ground movements due to shallow tunnelling. In Proc. $2^{\text {nd }}$ Int. Conference on Soil Structure Interaction in Urban Civil Engineering, ETH Zürich, pages 365-376, 2002.

[8] R. J. Finno and M. Calvello. Supported excavations: Observational method and inverse modelling. Journal of Geotechnical and Geoenvironmental Engineering ASCE, 131(7):826-836, 2005 .

[9] J. N. Franzius, D. M. Potts, and J. B. Burland. The influence of soil anisotropy and $K_{0}$ on ground surface movements resulting from tunnel excavation. Géotechnique, 55(3):189-199, 2005.

[10] A. Grammatikopoulou, L. Zdravković, and D. M. Potts. The behaviour of 'bubble' models in tunneling problems. In Proc. $2^{\text {nd }}$ Int. Conference on Soil Structure Interaction in Urban Civil Engineering, Zürich, 2002.

[11] G. Gudehus, A. Amorosi, A. Gens, I. Herle, D. Kolymbas, D. Mašín, D. Muir Wood, R. Nova, A. Niemunis, M. Pastor, C. Tamagnini, and G. Viggiani. The soilmodels.info project. International Journal for Numerical and Analytical Methods in Geomechanics, 32(12):1571-1572, 2008

[12] G. Gudehus and D. Mašín. Graphical representation of constitutive equations. Géotechnique, 52(2):147-151, 2009.

[13] M. J. Gunn. The prediction of surface settlement profiles due to tunnelling. In G. T. Houlsby and A. N. Schofield, editors, Predictive soil mechanics: Proceedings of the Worth Memorial Symposium, London, pages 304-316. Thomas Telford, London, 1993.

[14] V. Hájek, D. Mašín, and J. Boháč. Capability of constitutive models to simulate soils with different OCR using a single set of parameters. Computers and Geotechnics, 36(4):655-664, 2009.

[15] V. Horák. Kralovo pole tunnel in Brno from designer point of view. Tunel, 18(1):67-72, 2009.

[16] V. Horák. Traffic solution for the I/42 road, Brno, LCCR Dobrovského. Tunel, 18(1):61-66, 2009.

[17] J. Jáky. Pressures in silos. In Proc. $2^{\text {nd }}$ Int. Conf. Soil Mechanics, volume 1, pages 103-107. Rotterdam, 1948.

[18] T. W. Lambe. Predictions in soil engineering. Géotechnique, 23(2):149-202, 1973. 
[19] D. Mašín. A hypoplastic constitutive model for clays. International Journal for Numerical and Analytical Methods in Geomechanics, 29(4):311-336, 2005.

[20] D. Mašín. A hypoplastic constitutive model for clays with meta-stable structure. Canadian Geotechnical Journal, 44(3):363-375, 2007.

[21] D. Mašín. 3D modelling of a NATM tunnel in high $K_{0}$ clay using two different constitutive models. Journal of Geotechnical and Geoenvironmental Engineering ASCE, 135(9):1326$1335,2009$.

[22] D. Mašín, C. Tamagnini, G. Viggiani, and D. Costanzo. Directional response of a reconstituted fine grained soil. Part II: performance of different constitutive models. International Journal for Numerical and Analytical Methods in Geomechanics, 30(13):1303-1336, 2006.

[23] P. W. Mayne and F. H. Kulhawy. $K_{0}-\mathrm{OCR}$ relationships in soil. In Proc. ASCE J. Geotech. Eng. Div., volume 108, pages 851-872, 1982.

[24] J. Najser and J. Boháč. Measurement of critical state strngth in the ring shear apparatus (in Czech). In In Proc. $33^{\text {th }}$ Conf. Zakládání Staveb. Brno, Czech Republic, 2005.

[25] A. Niemunis and I. Herle. Hypoplastic model for cohesionless soils with elastic strain range. Mechanics of Cohesive-Frictional Materials, 2:279-299, 1997.

[26] P. P. Oreste. A procedure for determining the reaction curve of shotcrete lining considering transient conditions. Rock Mechanics and Rock Engineering, 36(3):209-236, 2003.

[27] J. Pavlík, L. Klímek, and D. Rupp. Geotechnical exploration for the Dobrovského tunnel, the most significant structure on the large city ring road in Brno. Tunel, 13(2):2-12, 2004.

[28] J. Pavlík and D. Rupp. The large city ring road Brno, section I/42 Dobrovského A, exploratory adits (in Czech). Technical report, Geotechnical site investigation, Geotest Brno, 2003.

[29] E. P. Poeter and M. C. Hill. Documentation of UCODE, a computer code for universal inverse modelling. Technical report, US Geological Survey Water Resources Investigations Report 98-4080, 1998.

[30] R. Pöttler. Time-dependent rock-shotcrete interaction. A numerical shortcut. Computers and Geotechnics, 9:149-169, 1990.

[31] D. Rodemann. Tochnog Professional user's manual. http://www.feat.nl, 2008.

[32] K. H. Roscoe and J. B. Burland. On the generalised stress-strain behaviour of wet clay. In J. Heyman and F. A. Leckie, editors, Engineering Plasticity, pages 535-609. Cambridge: Cambridge University Press, 1968.

[33] K. Schikora and T. Fink. Berechnungsmethoden moderner bergmännischer Bauweisen beim U-Bahn-Bau. In: Bauingenieur, pages 193-198, 1982.

[34] T. Svoboda and D. Mašín. Impact of a constitutive model on inverse analysis of a NATM tunnel in stiff clays. In V. K. Kajnlia, T. Ramamurthy, P. P. Wahi, and A. C. Gupta, editors, Proc. ITA-AITES World Tunnel Congress, Agra, India, volume 2, pages 627-636. Springer, Berlin, 2008. 
[35] T. Svoboda and D. Mašín. Optimisation of parameters for simulating a natm tunnel in stiff clays based on a 3d model of exploratory adit. In G. Meschke, G. Beer, J. Eberhardsteiner, D. Hartmann, and M. Thewes, editors, Proc. $2^{\text {nd }}$ International Conference on Computational Methods in Tunnelling EURO:TUN 2009, volume 1, pages 249-256, 2009.

[36] T. Svoboda and D. Mašín. Capability of a load-rediction method to predict displacement field due to NATM tunnelling in clays. Tunnelling and Underground Space Technology (Under review), 2010.

[37] M. Yazdchi, S. R. Macklin, and H.-C. Yeow. 3D modelling of sprayed-concrete-lined tunnels in clay. Geotechnical Engineering, Proc. Inst. Civil. Eng., London, 159(GE4):243-250, 2006.

[38] I. Zemánek, J. Lossmann, and K. Socha. Impact of exploration galleries for the Dobrovského tunnel on surface development in Brno; application of the observation method. Tunel, 12(3):33-37, 2003. 